\title{
6. Whistleblower mistreatment: identifying the risks
}

\section{A. J. Brown and Jane Olsen}

\section{Introduction}

The previous chapter confirmed that even when the reporting of wrongdoing is vindicated, many public interest whistleblowers experience stress and difficulty. On average, it is a minority of whistleblowers who report bad treatment from management or co-workers (between 20 and 30 per cent), but this proportion is still sizeable, has direct impacts on the willingness of others to report and in some public agencies runs to a very much higher figure. Fairness, justice and the importance of fostering a positive reporting climate dictate that it is in everyone's interests - from whistleblowers to governments - to reduce this proportion to the lowest possible level. How is this goal best pursued?

Much of the answer lies in Part 2 of this book, which reviews the systems and procedures that public agencies currently have in place for the management of whistleblowing. Before leaving the data on the hundreds of individual whistleblowing incidents captured by this research, it is useful to mine this for a better understanding of which circumstances are most closely associated with higher levels of reprisal risk. Although mistreatment can arise in any type of whistleblowing case, clearly there are some types of cases in which the risks are generally higher. Identifying these not only helps complete the picture on the nature and impact of these types of whistleblowing outcomes, it is of practical importance in helping identify how agencies can better anticipate and manage reprisal risks.

Given the volume of whistleblowing that occurs and the fact that a large proportion can clearly be managed to a positive conclusion, it is logical that efforts to prevent and contain mistreatment should be focused on those cases involving the greatest risks. As will be seen in Chapter 9, there are currently few organised methods for assessing the risks that a reprisal will follow a particular act of whistleblowing. Moreover, it is already clear from Chapter 5 that some existing assumptions about likely sources of conflict and reprisal risk are misplaced. Effective appreciation of the risks, in individual cases, becomes important from a wide range of perspectives.

This chapter draws on the employee and internal witness surveys to identify those cases that might be considered at 'higher risk' of mistreatment and, in turn, the particular characteristics that contribute to the complexity of those cases. The core measure used is the third dimension studied in Chapter 5: whether 
respondents who reported wrongdoing said they felt themselves to have been treated well, the same or badly by management or by co-workers as a result of their whistleblowing.

The analysis is broken into three sections. First, the chapter continues an examination of the subjective elements of perceived mistreatment - in particular, the role of gaps between whistleblowers' expectations of what will happen and what actually happens. By analysing the relationships between whistleblowers' expectations about their treatment and the results, it is seen that employees often have expectations of positive treatment - no doubt reinforced by official efforts to encourage internal whistleblowing - that are not always met. It is also seen that this is not necessarily because the expectations are unrealistic. Whistleblowers are usually relatively accurate in self-assessing the reaction of co-workers to their disclosure, with their major problems arising in predicting the reaction of management. These results combine with those in the previous chapter to emphasise that whistleblowers are more likely to need support in navigating the management response to their disclosure, including the risk of management reprisals, than in anticipating and managing risks from co-workers. The implications of this are discussed further in the conclusion.

The second part of the chapter looks to the employee survey data to identify the 'risk factors' that point to circumstances in which it is more likely that a given disclosure will result in reported mistreatment. Logistic regression is used to compare public interest whistleblowers who do not report bad treatment (either from management or from co-workers) with those who do, across a range of variables. The result is a hierarchy of risk factors that agencies can use to identify those cases in which there is a higher likelihood of mistreatment. Where these factors combine, the proportion of whistleblowers who currently suffer mistreatment is very much higher than the average results indicated in Chapter 5. The key risk factors for whistleblower mistreatment by co-workers are identified, in order of significance, as:

1. wrongdoing that is perceived as more serious

2. lack of any positive outcome from investigation

3. involvement of more than one person in the alleged wrongdoing

4. situation of the whistleblower in a work group of less than 20 people.

The key risk factors for mistreatment by management are identified as:

1. investigations that are not resolved internally and become external

2. lack of any positive outcome from investigation

3. wrongdoing directed at the whistleblower personally

4. involvement of wrongdoers employed at a higher organisational level

5. wrongdoing that is perceived as more serious and/or frequent. 
The third part of this chapter reinforces this picture of reprisal risk factors, by undertaking two further comparisons. The analysis shows that a 'higher-risk' whistleblower could be considered to be one whose disclosure has not been substantiated and who has gone external to the organisation-yet, despite the odds, sometimes these report having been treated the same or well. What factors are associated with these cases, which do not turn out as badly as might be feared? Conversely, a 'lower-risk' whistleblower can be considered to be one who has been able to report internally and whose report is acted on with a positive substantive result. In theory, such whistleblowers should be easier for management to protect, however, some still report mistreatment, prompting the question: what crucial factors turn this potential success into a failure? These analyses confirm the salience of the factors listed above, providing new guidance on the processes that public agencies can use to better assess, reduce and manage the risks of whistleblower mistreatment.

\section{Expectations of treatment and support}

Employees' experiences of reporting wrongdoing are shaped by objective and subjective elements: how they were really treated and how they feel they were treated. Outcomes also depend on the results relative to the expectations of employees about how they were likely to fare. As seen in Chapters 3 and 4 , otherwise similar employees can arrive at very different assessments of how they will be treated, depending on the circumstances. This has direct implications for their differing decisions about whether to report and, if so, how to report. Their assessment of the risks also then shapes their interactions with authorities and colleagues and how they anticipate and manage their particular circumstances. Based on experience with public sector whistleblowers in Queensland, Anderson (1996) suggested that these different approaches to risk could place employees who observed wrongdoing in any one of a number of categories.

- Risk avoiders, who overestimate risks of reprisal, have low knowledge of or confidence in protection and are unlikely to come forward.

- Risk managers, who can realistically anticipate the risks and are more likely to come forward if they see a reasonable prospect of support.

- Trusting whistleblowers, who might anticipate a risk of reprisal but come forward expecting the risks to be lower than they perhaps are.

- Naive whistleblowers, who come forward unaware that there are risks of reprisal and who are therefore often at higher risk.

- 'Kamikaze' whistleblowers, who come forward regardless of risk and therefore, depending on the circumstances, could be at very high risk.

Much of the employee survey data bear out this range of expectations. In Chapter 3 , those who observed wrongdoing but took no action most often did so in 
circumstances in which there were obvious risks to be avoided, often for the explicit reason that that was the case. Table 6.1 extends this picture by comparing respondents' overall expectations about treatment and support, between all those who did not observe wrongdoing, those who observed but did not report and those who did report outside their role. The comparison confirms that those who did not report had lower than average expectations of support and higher than average expectations of mistreatment. Those who reported had slightly more negative attitudes again. This is another sign of the pattern that emerged from Chapters 3, 4 and 5-that even when they do not result in active mistreatment, the experiences of observing and reporting wrongdoing often result in a reduction in employees' trust and confidence in the organisation.

\section{Table 6.1 Comparison of expectations relating to risk of reprisals (mean)}

\begin{tabular}{|c|c|c|c|c|}
\hline $\begin{array}{l}1=\text { strongly disagree } \\
2=\text { disagree } \\
3=\text { neither disagree/agree } \\
4=\text { agree } \\
5=\text { strongly agree }\end{array}$ & 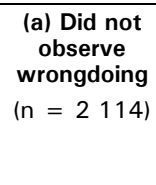 & $\begin{array}{l}\text { (b) Observed } \\
\text { wrongdoing but } \\
\text { did not report } \\
(n=3245)\end{array}$ & $\begin{array}{c}\text { (b) Observed } \\
\text { wrongdoing, } \\
\text { reported outside } \\
\text { role } \\
(n=1470)\end{array}$ & $\begin{array}{c}\text { Total }^{\text {a }} \\
\text { (n }=7474)\end{array}$ \\
\hline $\begin{array}{l}\text { Management is serious about } \\
\text { protecting people who report } \\
\text { wrongdoing }\end{array}$ & 3.45 & 3.04 & 2.93 & 3.17 \\
\hline $\begin{array}{l}\text { I am confident that my rights will be } \\
\text { protected if I report wrongdoing and } \\
\text { am retaliated against }\end{array}$ & 3.46 & 3.01 & 2.95 & 3.16 \\
\hline $\begin{array}{l}\text { I will suffer negative consequences } \\
\text { from management for reporting } \\
\text { wrongdoing }\end{array}$ & 2.53 & 2.91 & 3.01 & 2.78 \\
\hline $\begin{array}{l}\text { I will suffer negative consequences } \\
\text { from my fellow employees for } \\
\text { reporting wrongdoing }\end{array}$ & 2.75 & 3.10 & 3.13 & 2.97 \\
\hline
\end{tabular}

${ }^{a}$ Includes role reporters and 30 reporters of whom it was unknown whether they could be classified as role or non-role reporters.

Source: Employee survey: Q18.

This pattern is also reinforced by Table 6.2, which shows the results for a range of attitudinal variables used in Chapters 3 and 4 for all public interest whistleblowers in the employee survey grouped according to their treatment. While the direction of any causality is again impossible to state, the most likely explanation for the significant differences is that the experience of reporting has impacted on personal attitudes to work, the organisation and others, more than the other way around. Equally important is the continuing lack of significant difference between the groups on many of these attitudinal variables (especially 'initiative' and 'industry') and the fact that even when differences occur, the results for whistleblowers who are treated badly remain at or above the mean. For example, on average, job satisfaction still does not fall into negative territory even for those treated badly by management. For those whistleblowers treated badly by management, the only organisational citizenship sub-scale on which this group scored lower was 'loyalty', which is again likely to be explained by their negative experience. 
Just as Chapter 3 shows that personal attitudes cannot safely predict who will blow the whistle, these results confirm that they cannot be used to predict who will report that they suffered mistreatment. Overall, the data do not show that those whistleblowers who said they were mistreated were any more likely to be troublemakers, disgruntled employees or individuals predisposed to fall into conflict with management than those who were treated well or the same. While an existing history of poor performance, low job satisfaction and conflict with others would inevitably complicate any whistleblowing incident, there is no evidence that these are the typical features of the whistleblowers who report a bad experience.

Table 6.2 Whistleblower treatment by whistleblower attitudes (mean)

\begin{tabular}{|c|c|c|c|c|}
\hline $\begin{array}{l}\text { Whistleblower attitudes } \\
1=\text { very low to } \\
5=\text { very high }\end{array}$ & $\begin{array}{c}\text { (1a) Treated } \\
\text { well/same by } \\
\text { management } \\
(n=735)\end{array}$ & $\begin{array}{c}\text { (1b) Treated } \\
\text { badly by } \\
\text { management } \\
(\mathrm{n}=160)\end{array}$ & $\begin{array}{c}\text { (2a) Treated } \\
\text { well/same by } \\
\text { co-workers } \\
(\mathrm{n}=801)\end{array}$ & $\begin{array}{c}\text { (2b) Treated } \\
\text { badly by } \\
\text { co-workers } \\
(\mathrm{n}=77)\end{array}$ \\
\hline Trust in management & $3.38^{* * * *}$ & $2.44^{* * * *}$ & $3.27^{* * * *}$ & $2.58^{* * * *}$ \\
\hline Job satisfaction & $3.53^{* * * *}$ & $3.01^{* * * *}$ & $3.44^{*}$ & $3.26^{*}$ \\
\hline Organisational citizenship behaviour & $3.84^{* * *}$ & $3.72^{* * *}$ & 3.81 & 3.86 \\
\hline Helping co-workers & 4.01 & 4.07 & $4.00^{* *}$ & $4.15^{* *}$ \\
\hline Initiative & 3.85 & 3.82 & 3.84 & 3.87 \\
\hline Industry & 3.89 & 3.89 & 3.87 & 4.01 \\
\hline Loyalty & $3.62^{* * * *}$ & $3.14^{* * * *}$ & 3.54 & 3.42 \\
\hline
\end{tabular}

* difference statistically significant at $\mathrm{p}<0.05$

** difference statistically significant at $\mathrm{p}<0.01$

*** difference statistically significant at $\mathrm{p}=0.001$

**** difference statistically significant at $\mathrm{p}<0.0005$

Source: Employee survey: Q1, Q2.

The data in Tables 6.1 and 6.2 also reinforce the results from Chapters 3 and 4 that most whistleblowers enter into the process with a high degree of trust. Another feature of Table 6.1 is the extent to which all the expectations hover around the mean. This indicates that, while the bulk of respondents might not be harbouring strong fears about the organisational responses, they also do not appear to have a strong knowledge of or confidence in what those responses will be. It appears that a large proportion of public interest whistleblowers fall into the 'trusting whistleblower' category, with many also probably quite naive - for no fault of their own - about the processes involved.

Table 6.3 compares the same respondents according to the reasons they gave for reporting the wrongdoing, including some more specific indicators of their confidence that they would be supported or protected (bolded items). Whistleblowers who were mistreated placed a higher level of importance on all reasons than those who were not mistreated. On some variables, this could reflect the nature of the wrongdoing (for example, the fact that it was more serious), but the pattern could also suggest that individuals with negative experiences hold a stronger opinion about the importance of their act of whistleblowing, 
whether before or after they suffer mistreatment (or both). Most importantly, while expectations of support and protection remained only second-order reasons for reporting, they were stated as significantly more important for those who were then treated badly (especially by management) than for those treated the same or well. In other words, at least in retrospect, whistleblowers who were treated badly also appeared to have had higher original expectations about support and lower expectations that they would be left exposed to risks.

These results show that a higher degree of trust or naivety regarding the risk of a bad experience is probably a very good indicator that such a risk will be realised. In many respects, this stands to reason and comes as a reminder of the many subjective elements in any individual's assessment of the outcome. Lower expectations are by definition usually more easily met and outcomes are therefore regarded as relatively good; but if expectations are high, meeting them is more complex and an identical outcome could be seen as relatively bad. As seen in Chapter 5, small misunderstandings or failures in communication about the response to a disclosure can be enough to begin a breakdown in trust from which it is difficult to recover.

Table 6.3 Whistleblower treatment by reasons for reporting (mean)

\begin{tabular}{|c|c|c|c|c|}
\hline $\begin{array}{l}1=\text { not at all important } \\
2=\text { somewhat important } \\
3=\text { very important } \\
4=\text { extremely important }\end{array}$ & $\begin{array}{c}\text { (1a) Treated } \\
\text { well/same by } \\
\text { management } \\
(n=647)\end{array}$ & $\begin{array}{c}\text { (1b) Treated } \\
\text { badly by } \\
\text { management } \\
(\mathrm{n}=147)\end{array}$ & $\begin{array}{c}\text { (2a) Treated } \\
\text { well/same by } \\
\text { co-workers } \\
(\mathrm{n}=721)\end{array}$ & $\begin{array}{l}\text { (2b) Treated } \\
\text { badly by } \\
\text { co-workers } \\
(\mathrm{n}=73)\end{array}$ \\
\hline $\begin{array}{l}\text { I saw it as my ethical responsibility to } \\
\text { report it }\end{array}$ & $3.15^{* * * *}$ & $3.41^{* * * *}$ & $3.16^{* * *}$ & $3.48^{* * *}$ \\
\hline The wrongdoing was serious enough & $2.97^{* * * *}$ & $3.32^{* * * *}$ & $3.00^{* * * *}$ & $3.32^{* * * *}$ \\
\hline I had evidence to support my report & $2.91^{* * * *}$ & $3.32^{* * * *}$ & $2.95^{* * * *}$ & $3.38^{* * * *}$ \\
\hline $\begin{array}{l}\text { I believed that my report would help to } \\
\text { correct the problem }\end{array}$ & $3.04^{*}$ & $3.21^{*}$ & $3.04^{* *}$ & $3.34^{* *}$ \\
\hline $\begin{array}{l}\text { I thought that I would be supported by } \\
\text { management }\end{array}$ & $2.83^{*}$ & $2.99^{*}$ & $2.82^{* * *}$ & $3.19^{* * *}$ \\
\hline I knew who I should report to & 2.85 & 2.97 & $2.83^{* * *}$ & $3.16^{* * *}$ \\
\hline $\begin{array}{l}\text { I thought that I would be supported by } \\
\text { my co-workers }\end{array}$ & $2.58^{* * * *}$ & $2.93^{* * * *}$ & 2.64 & 2.78 \\
\hline $\begin{array}{l}\text { I believed I was under a legal } \\
\text { responsibility to report it }\end{array}$ & $2.63^{*}$ & $2.86^{*}$ & $2.62^{* * * *}$ & $3.09^{* * * *}$ \\
\hline $\begin{array}{l}\text { I believed I would have legal protection } \\
\text { if I reported }\end{array}$ & $2.36^{* * * *}$ & $2.79^{* * * *}$ & $2.41^{* * * *}$ & $2.87^{* * * *}$ \\
\hline I trusted the person I should report to & $2.92^{*}$ & $2.72^{*}$ & 2.87 & 2.95 \\
\hline
\end{tabular}

* difference statistically significant at $\mathrm{p}<0.05$

** difference statistically significant at $\mathrm{p}<0.01$

*** difference statistically significant at $\mathrm{p}=0.001$

**** difference statistically significant at $\mathrm{p}<0.0005$

Source: Employee survey: Q27.

The problem for agencies is that efforts to promote a higher consciousness of the risks among employees, before they report, will succeed only in converting potential whistleblowers into 'risk avoiders' who do not report at all. In other words, the encouragement of reporting relies on encouraging employees to be 
trusting, but this in itself will encourage higher expectations than might otherwise be held.

The only relief from this catch-22 situation is to ensure that there is an accurate assessment of the risks of mistreatment as soon as an employee makes a disclosure, in a manner that encourages whistleblowers and those responsible for them to proceed to manage these risks with a shared understanding. The importance of this risk-management approach has already been shown by the data in Chapter 5, which showed a mismatch between the outcomes of greatest apparent importance to whistleblowers and the assessments of most case-handlers and managers.

The need for such an approach is also underscored by the evidence of significant differences between the assessments reached by employees about the risk of mistreatment by their co-workers and the risk of mistreatment by managers. As seen in Chapter 5, until now, it has been widely believed that reprisals against whistleblowers are more likely to come from co-workers than from management. The results in Tables 6.1 and 6.3 confirm that this expectation is shared by many whistleblowers themselves. The analysis of outcomes in Chapter 5, however, reveal that co-workers per se are only infrequently the main sources of bad treatment or harm against those who do blow the whistle, with management more likely to be the main source of perceived mistreatment in practice. A contrasting result in Chapter 3 was that, in a majority of cases in which a fear of reprisal was given as a reason for not reporting, supervisors and managers were implicated in the wrongdoing.

These contrasting data suggest that while 'risk avoiders' who do not report are particularly conscious of the risk of mistreatment by management, the large body of more 'trusting' whistleblowers typically underestimates this risk. Results from the internal witness survey add to this picture. Table 6.4 sets out how all respondents to this survey answered further questions about their expectations of good and bad treatment. Unlike the employee survey respondents, this particular group said that they anticipated mistreatment by management as being more likely than mistreatment by co-workers. In other respects, however, their expectations appear relatively typical. Table 6.5 then shows the relationship between the level of support expected by internal witness respondents from management and co-workers respectively and their experience of how they were ultimately treated. There was a very strong inverse relationship between expecting support from co-workers and mistreatment by co-workers $(\mathrm{p}<0.001)$, meaning that these expectations were usually right: if a reporter had low expectations of support from co-workers, they were more likely to report bad treatment from them.

The same was not true in relation to management. There was no identifiable relationship between the level of support expected by reporters from management 
and how they were treated. Clearly, on the whole, the reactions of management were more negative than reporters anticipated. The most crucial result, however, is that, notwithstanding the importance of the management reaction to their prospects, the same reporters were far less able to accurately predict the reaction of management.

Table 6.4 Internal witness expectations of support, reprisals and protection (per cent and mean)

\begin{tabular}{|c|c|c|c|c|c|c|}
\hline & $\begin{array}{c}\text { (1) } \\
\text { Not at all }\end{array}$ & $\begin{array}{c}\text { (2) } \\
\text { Not very }\end{array}$ & $\begin{array}{c}\text { (3) } \\
\text { Somewhat }\end{array}$ & $\begin{array}{l}(4) \\
\text { Very }\end{array}$ & \begin{tabular}{c|}
$(5)$ \\
Extremely
\end{tabular} & $\begin{array}{c}\text { Mean } \\
\text { (SD) }\end{array}$ \\
\hline $\begin{array}{l}\text { How supportive did you expect } \\
\text { management to be? }\end{array}$ & $14(30)$ & $15(32)$ & $16(34)$ & $32(67)$ & $24(50)$ & $\begin{array}{l}3.35 \\
(1.36)\end{array}$ \\
\hline $\begin{array}{l}\text { How supportive did you expect } \\
\text { immediate co-workers to be? }\end{array}$ & $10(22)$ & $14(29)$ & $21(44)$ & $35(75)$ & $20(43)$ & $\begin{array}{c}3.41 \\
(1.24)\end{array}$ \\
\hline $\begin{array}{l}\text { How likely did you think it was that } \\
\text { managers would take action against } \\
\text { you? }\end{array}$ & 21 (45) & $28(60)$ & $22(47)$ & $16(33)$ & $13(28)$ & $\begin{array}{c}2.71 \\
(1.32)\end{array}$ \\
\hline $\begin{array}{l}\text { How likely did you think it was that } \\
\text { co-workers would take action against } \\
\text { you? }\end{array}$ & 31 (65) & $31(66)$ & $22(46)$ & $11(23)$ & $6(13)$ & $\begin{array}{c}2.31 \\
(1.19)\end{array}$ \\
\hline $\begin{array}{l}\text { How likely did you think it was that you } \\
\text { would be effectively protected? }\end{array}$ & $14(30)$ & $26(55)$ & $28(60)$ & $21(44)$ & $11(24)$ & $\begin{array}{c}2.89 \\
(1.21)\end{array}$ \\
\hline
\end{tabular}

${ }^{a}$ Correlation between expectation of management and co-worker support is statistically significant (Pearson $\mathrm{r}=0.404 ; \mathrm{p}<0.0005)$.

Source: Internal witness survey: Q17, Q18, Q20, Q21, Q22 ( $\mathrm{n}=213)$.

Table 6.5 Relationship between expectations of support and treatment

\begin{tabular}{ll|l}
\hline Relationship between... & \multicolumn{1}{c}{ Correlation } \\
\hline $\begin{array}{l}\text { Expectation of management support } \\
1=\text { not at all to } 5=\text { extremely likely }\end{array}$ & $\begin{array}{l}1=\text { extremely well to } 5= \\
\text { extremely badly }\end{array}$ & $\begin{array}{l}\text { Pearson } r=0.040 \\
\text { Not sig. at } \mathrm{p}=0.562 \\
(\mathrm{n}=211)\end{array}$ \\
\hline $\begin{array}{l}\text { Expectation of co-worker support } \\
1=\text { not at all to } 5=\text { extremely likely }\end{array}$ & $\begin{array}{l}1=\text { extremely well to } 5= \\
\text { extremely badly }\end{array}$ & $\begin{array}{l}\text { Pearson } r=-0.375 \\
\text { Sig. at } \mathrm{p}<0.0005 \\
\text { ( } \mathrm{n}=208)\end{array}$ \\
\hline
\end{tabular}

${ }^{\text {a }}$ It was anticipated that these correlations would be negative because these outcome scales run from a good outcome scoring lowest to a poor outcome scoring highest.

Source: Internal witness survey: Q17, Q18, Q50, Q51.

In summary, while employees' judgments of risk appear rational, there are limits on the extent to which employees who report wrongdoing can be expected to self-assess and self-manage these risks in a comprehensive manner. The nature of the process dictates that many whistleblowers will be trusting or somewhat naive about the risks of mistreatment, because otherwise they will be more likely to follow a risk-avoidance path and simply not report. Most whistleblowers are nevertheless capable of accurately assessing the risks of mistreatment from their co-workers and are therefore better placed to manage these risks from the outset. The data suggest, however, that, just as many case-handlers and managers might not have an accurate assessment of the issues of most importance to whistleblowers, many whistleblowers might have difficulty anticipating when 
management is likely to react negatively to a report of wrongdoing, or otherwise fail to deliver the promised support.

There are many possible reasons why management reactions can be difficult to anticipate. Employees know from firsthand experience about the attitudes and personalities of their co-workers, but they might have little or no knowledge of the complex ways in which organisations must often handle investigations. They might report wrongdoing without realising that managers were involved or were already aware of the wrongdoing but had allowed it to continue. Even when employees have reason to believe that some managers will recognise that a problem needs to be fixed, they might not be aware of the extent to which others will see its exposure as potentially embarrassing.

These results emphasise the considerable extent to which the accurate, objective assessment of risk is a precondition for the effective management of many whistleblowing incidents. Unless an agreed understanding is reached about the sources and levels of risk from an early point in the reporting process, the prospects for successfully managing either the expectations or the real experiences of whistleblowers are immediately more doubtful. Risk assessment is crucial to closing the gaps in whistleblowers' understanding of how others might perceive their report and reducing the potential for conflict, including conflict with management about whether effective support was provided.

\section{Risk factors for mistreatment of whistleblowers}

Clearly not all whistleblowing cases need to be managed equally intensively. Part of the utility of a risk-assessment approach is in helping identify which cases are more likely to warrant early intervention and active management. From the previous section, it can be seen that one indicator of high risk is subjective: the risk that expectations will not be met is naturally higher whenever a whistleblower has unrealistically low expectations about the chances of adverse reactions. At the same time, there could be other more objective indicators of risk.

In the United States, a number of studies have sought to identify the factors that predict retaliation against whistleblowers (Near and Miceli 1996; Miceli et al. 1999). Near and Miceli (1996) classified the predictors of retaliation into four categories.

1. Personal characteristics of the whistleblower and of the job situation that influence retaliation (for example, gender and other demographic variables; personality and other individual difference variables, such as OCB).

2. Organisational variables that are concerned with the context in which whistleblowing occurs and are relatively enduring characteristics of the 
organisation or the reporter's work group (for example, size of organisation/work group, structure, ethical culture).

3. Characteristics of the wrongdoing (for example, seriousness, systematic), which will affect the process by which reporting occurs and is responded to (for example, provision of support, external reporting).

4. The power and status of the wrongdoer, which can influence whether the organisation protects or sanctions them (for example, seniority, tenure in the organisation).

The relative importance of each of these factors was considered in a sample of federally employed reporters (Miceli et al. 1999). Whistleblowers who suffered retaliation did not reliably differ from other whistleblowers in terms of most personal characteristics, such as age, gender, race, tenure in the organisation, pay, being a professional and so on. Whistleblowers with negative experiences, however, often felt that they had less support than others from managers and supervisors (notably, not from co-workers) and they were more likely to have used external channels to report the wrongdoing, rather than internal channels exclusively. The seriousness of the wrongdoing was also a fairly consistent predictor of retaliation.

Alternatively, an interview study of private sector employees indicated that no special method of disclosure or personal characteristics insulated whistleblowers from reprisals (Rothschild and Miethe 1999), while research in a large military base found that only gender predicted reprisals: women were more likely to suffer retaliation than men (Near et al. 2004). While these studies suggest a number of important factors to consider, they highlight the fact that predictors of poor treatment differ depending on the context in which the whistleblowing occurs. Which predictors of poor treatment appear to have currency in the context of the Australian public sector?

To examine the level of association between various risk factors and the poor treatment of whistleblowers, further analysis was conducted into the data provided by all public interest whistleblowers in the employee survey $(n=913)$. A logistic regression technique ${ }^{l}$ was used to identify the relative importance of a range of variables in those cases that resulted in perceived mistreatment. By simultaneously controlling for a number of factors, logistic regression can identify the unique effect that each factor has on the variable(s) of interest - in this case, bad treatment by managers or co-workers. While the analysis cannot show causality, it shows where there is a strong association between a particular outcome and particular factors, helping identify not only the significant factors in isolation, but their relative significance in combination.

A large group of risk factors from the employee survey was selected for inclusion in the analysis based on previous studies and preliminary findings. This consisted of a variety of personal, organisational, wrongdoing and power characteristics. ${ }^{2}$ 
A first analysis established the extent to which each of these variables helped predict the likelihood of a respondent belonging to one of two groups: 1) those who said they were treated badly by co-workers; and 2) those who said they were treated the same or well by co-workers. The analysis was then repeated for the more complex problem of mistreatment by management, recognising that reprisals stemming from these two groups could have different explanatory factors.

\section{Mistreatment by co-workers}

After adjusting for all variables in the model, the risk factors found to be significantly associated with poor treatment by co-workers are shown in Table 6.6. The column of particular note in this table is the 'odds ratio': this presents the probability of a public interest whistleblower experiencing poor treatment divided by the probability of them experiencing good or similar treatment. An odds ratio greater than 1 indicates higher odds of poor treatment.

The findings highlight four key risk factors associated with the poor treatment of whistleblowers by co-workers. The odds of being treated badly by co-workers were:

1. three and a half times greater when the wrongdoing was perceived to be more serious

2. more than three times greater if the report of wrongdoing did not have a positive outcome (that is, things did not become better as a result of investigation into the report)

3. more than two and a half times greater when more than one person was involved in the alleged wrongdoing

4. more than twice as great when the size of the whistleblower's work group was less than 20 people.

Table 6.6 Risk factors for poor treatment of whistleblowers by co-workers ${ }^{3}$

\begin{tabular}{|c|c|c|c|c|c|c|}
\hline Risk factors & $\begin{array}{c}\text { Coefficient } \\
(\beta)\end{array}$ & $\begin{array}{l}\text { Standard } \\
\text { error }\end{array}$ & Wald $\chi^{2}$ & P-value & Odds ratio & $95 \% \mathrm{Cl}$ \\
\hline The wrongdoing was serious & 1.25 & 0.27 & 20.85 & $<0.0005$ & 3.49 & $2.04-6.00$ \\
\hline $\begin{array}{l}\text { No positive outcome from } \\
\text { investigation }\end{array}$ & 1.17 & 0.36 & 10.78 & 0.001 & 3.23 & $1.60-6.50$ \\
\hline $\begin{array}{l}\text { More than one person involved in } \\
\text { wrongdoing }\end{array}$ & 1.02 & 0.35 & 8.52 & 0.004 & 2.77 & $1.40-5.47$ \\
\hline $\begin{array}{l}\text { Size of immediate work group } \\
<20 \text { people }\end{array}$ & 0.75 & 0.37 & 4.16 & 0.041 & 2.12 & $1.03-4.37$ \\
\hline
\end{tabular}

Source: Employee survey: Q22, Q24, Q33, Q49 ( $=488)$.

This group of risk factors confirms much of what was already suspected regarding the 9 per cent of whistleblowers identified in Chapter 5 as reporting co-worker mistreatment. It is also consistent with the conclusions in the previous section, that the major factors associated with the risk of co-worker reprisal are readily 
apparent to most whistleblowers and are more likely to be accurately assessed by them.

In particular, it makes sense that reporters who observed wrongdoing involving more than one person had greater odds of poor treatment, given the power inequality between a group of wrongdoers and a sole reporter and the increased likelihood that the wrongdoing had become part of the workplace culture. Similarly, when the size of the reporter's immediate workgroup is smaller, there is greater opportunity for direct or indirect reprisals (given the likely higher level of workplace interaction with the wrongdoer[s]) and there is more likely to be an environment conducive to them. These are indicators of a classically stereotypical reprisal situation.

The top two factors nevertheless have more interesting implications. Chapter 5 discussed a range of explanations for why a positive substantive outcome, such as substantiation of the report, played such a pivotal role in shaping the overall outcome of the whistleblowing incident. One explanation was that whistleblowers whose reports did not lead to positive action could be inclined to regard that result as itself constituting bad treatment - that is, they were simply dissatisfied. Given the overall pattern of results in Chapter 5, however, and the personal attitudinal variables in the previous section, this explanation would appear to fit only a limited number of cases. Moreover, this procedural dissatisfaction is not likely to be directed at their co-workers, but rather at the management processes responsible for the investigation result, as discussed further below.

A more salient explanation, therefore, is that in a range of circumstances, unless there is formal substantiation or other positive action that vindicates their report, the whistleblower could be 'fair game' for direct or indirect reprisals. At present, it appears that many internal whistleblowers are left in the position of having to emerge either as a 'winner' or 'loser' from the experience, rather than being left with the possibility of a more neutral outcome. In these situations, achieving substantive vindication becomes a primary factor in avoiding mistreatment, which could explain the degree of dependence on a positive substantive result described in Chapter 5.

The salience of this factor is reinforced by the role of the seriousness of the wrongdoing. It was hypothesised that more serious wrongdoing, once exposed, might not necessarily lead to a greater risk of co-worker reprisal because others were also more likely to share the whistleblowers' view of the seriousness of the matter. Conversely, it was thought that more petty matters could lead to higher reprisal risk, because co-workers would be more likely to agree with the alleged wrongdoer that the matter should never have been reported. This analysis confirms, however, that the more serious the perceived wrongdoing, the higher is the likelihood of co-worker reprisal, presumably because of the more serious 
consequences for the wrongdoers. Clearly, this risk then becomes extreme when the allegation is also not substantiated.

Two further hypotheses were also not supported by this analysis. Logically, some types of alleged wrongdoing could be thought to be more likely to trigger reprisal risks, depending on the impact of the allegations on the perceived wrongdoer. In Chapter 5, it was also pointed out that certain types of wrongdoing were more likely to be substantiated than others. This analysis shows, however, that it is these other factors - seriousness and lack of substantiation - that are associated most closely with co-worker mistreatment, irrespective of what type of wrongdoing is involved. In other words, while some types of wrongdoing can be objectively considered more 'serious' and also more difficult to substantiate, it is not the wrongdoing type itself but these results that dictate whether mistreatment is likely to follow. Any kind of wrongdoing can therefore give rise to these risks, depending on the circumstances.

Contrary to expectations, the level of confidentiality maintained in respect of the whistleblowing incident also failed to emerge as a significant predictor of mistreatment. In total, 83 per cent of whistleblowers who said that they were treated well or the same by co-workers and by management said that either 'no-one' or just 'a few' people knew they had reported the wrongdoing - compared with 63 per cent of those who were treated badly by co-workers, management or both. The fact that confidentiality did not emerge as a clear protective factor confirms that while it could be important, in most circumstances, it is either simply unachievable or plays no protective role. For example, even if only a few people ever know the whistleblower's identity, this usually includes the people most directly concerned. This result has significant implications for the strategies that agencies use to try to control reprisal risk and, in particular, the need for agencies to be ready with other intervention strategies at the point that confidentiality ceases to be practical.

\section{Mistreatment by management}

The second analysis examined the risk factors for mistreatment for those employee survey whistleblowers who indicated poor treatment from management (as distinct from co-workers). The results are set out in Table 6.7. The findings confirmed that, for the 18 per cent of whistleblowers who reported mistreatment by management, the factors associated with this result were more complex. Six key risk factors emerged, only two of which were common to mistreatment by co-workers. The odds of being treated badly by management were:

1. more than four and a half times greater in cases in which the investigation of wrongdoing did not remain internal to the organisation but progressed externally 
2. four times greater if the report of wrongdoing did not have a positive outcome (that is, things did not become better as a result of investigation into the report)

3. three and a half times greater when reporters become aware of the wrongdoing because it was directed at them rather than via other avenues

4. more than two and a half times greater when some or all of the wrongdoers were employed at a higher organisational level than the whistleblower

$5 \& 6$. also increased when the wrongdoing was perceived by the reporter to be serious or frequent.

Table 6.7 Risk factors for poor treatment of whistleblowers by management

\begin{tabular}{|c|c|c|c|c|c|c|}
\hline Risk factors & $\begin{array}{c}\text { Coefficient } \\
(\beta)\end{array}$ & $\begin{array}{c}\text { Standard } \\
\text { error }\end{array}$ & Wald $\chi^{2}$ & P-value & Odds ratio & $95 \% \mathrm{Cl}$ \\
\hline Investigation not kept internal & 1.54 & 0.35 & 19.52 & $<0.0005$ & 4.65 & $2.35-9.20$ \\
\hline $\begin{array}{l}\text { No positive outcome from } \\
\text { investigation }\end{array}$ & 1.41 & 0.32 & 19.07 & $<0.0005$ & 4.11 & $2.18-7.74$ \\
\hline $\begin{array}{l}\text { Reporter became aware of } \\
\text { wrongdoing because it was } \\
\text { directed at them }\end{array}$ & 1.26 & 0.31 & 16.81 & $<0.0005$ & 3.52 & $1.93-6.43$ \\
\hline $\begin{array}{l}\text { The wrongdoer was at a higher } \\
\text { level }\end{array}$ & 1.00 & 0.30 & 11.14 & 0.001 & 2.72 & $1.51-4.88$ \\
\hline The wrongdoing was serious & 0.59 & 0.21 & 8.14 & 0.004 & 1.80 & $1.20-2.70$ \\
\hline The wrongdoing was frequent & 0.40 & 0.16 & 6.34 & 0.012 & 1.48 & $1.09-2.02$ \\
\hline
\end{tabular}

Source: Employee survey: Q21, Q22, Q23, Q25, Q28, Q33 ( $=496)$.

The strongest common factor was the lack of any positive investigation result. This becomes an even stronger predictor of managerial mistreatment than of co-worker mistreatment. Its salience further confirms that, while some whistleblowers might be more likely than others to be dissatisfied by an unfavourable investigation result or push the matter in a way that generates more conflict, this is often likely to be the case because of the crucial protective value of achieving some form of vindication (fighting to emerge as a 'winner' rather than a 'loser'). The second common factor - the perceived seriousness of wrongdoing - was still present but not as important. This suggests that co-workers perhaps cannot be bothered reacting negatively in less serious matters, but that adverse management reactions can also flow in response to less serious matters, even though it is still more likely when the matters are serious.

The most dominant risk factor - the fact that managerial mistreatment is strongly associated with external reporting - combines with the issue of a substantive result to highlight again that any causality can run in either direction. Chapter 4 showed that most external whistleblowers had reported internally in the first instance. Therefore, it is likely that many whistleblowers are triggered to continue to pursue a disclosure externally because they experienced mistreatment within their organisation or because their claim could not be substantiated internally, or both. While it is more than possible that some whistleblowers experience mistreatment only after they disclose externally, in most cases, it can be presumed 
that external reporting follows the onset of reprisals or other conflict between the whistleblower and management, with external involvement then perhaps contributing to this real or perceived mistreatment in many cases.

This result nevertheless emphasises that in current circumstances-irrespective of the cause - by the time disclosures reach outside the organisation involved, crucial damage to the wellbeing of the whistleblower has often been done. This is further emphasised by the fact that this risk factor was not present for mistreatment by co-workers, but was the strongest of all factors associated with managerial mistreatment. These results further increase the obligations on agencies to manage their investigation and employee welfare processes actively and positively in the first instance. Failure to do so simply increases the likelihood of breakdowns in trust, external complaints and increasingly entrenched conflicts - all of which can have negative impacts on the organisation as well as any chance of a return to normality for the whistleblower.

The same results also support the conclusion that additional processes are needed to circumvent or reduce this risk of conflict, wherever internal processes are more likely to be tested by particular cases. Taken together, the remainder of the factors identify these classes of cases, in which the potential for internal processes to bring the matter to a successful conclusion is clearly more limited, at least without special measures or outside assistance. For example, it stands to reason that when a whistleblower reports a more serious or systemic matter, implicating managers, but an investigation does not or is not likely to resolve the matter in the whistleblower's 'favour', there is a very high risk that managerial action (or inaction) will occur that constitutes real or perceived mistreatment. This is clearly also compounded if the whistleblower feels that they are directly personally involved, with their capacity to independently self-manage the risks even further reduced, than if they are simply an observer or bystander.

Taken together, these factors emphasise why agencies need special processes for dealing with the welfare of the whistleblower and addressing the potential sources of conflict, outside the normal management chain. They also suggest the need for processes that monitor management responses to the whistleblower, before conflicts emerge or become too difficult to control. These issues, including the question of how earlier routine oversight by external integrity agencies might assist this process, are taken up in later chapters.

Again, it is salient that neither the wrongdoing type nor lack of confidentiality emerged as risk factors in this second analysis. Wrongdoing type could still remain indirectly relevant: not only are certain types of wrongdoing more likely to be substantiated than others, as shown in Chapter 5, certain types are more likely to come to the attention of whistleblowers as a result of having been directed at them personally, as shown in Chapter 3. It is, however, once again 
these other factors - lack of positive investigation outcome, personal involvement and, to a lesser extent, seriousness and frequency - that are most closely associated with management mistreatment, irrespective of what type of wrongdoing is involved. The absence of confidentiality as a protective factor is even less surprising than it is for co-worker mistreatment, given that, even if only a few people know, these are likely to be people in the management chain and are therefore well placed to undertake or be blamed for any reprisals.

The other very logical factor, confirming the realistic nature of these results, is that of the power differential between reporters and perceived wrongdoers. If more senior people are implicated, irrespective of their own level in the organisation, a whistleblower has double the chance of experiencing mistreatment from management, absent of any other factors. The lack of this factor in respect of co-worker mistreatment is perhaps unsurprising, but the difference tends to confirm that, overall, agencies have difficulty responding to upwards challenges to the integrity or competence of their own management. When other factors such as seriousness, frequency, personal involvement and difficulties in substantiation also combine, the risk of mistreatment is plainly extreme.

Taking both analyses together, it is clear that these very different listings of risk factors mean that the risks of mistreatment from each source need to be separated and independently assessed. The differences accord with the finding from Chapter 5 that only 5 per cent of whistleblowers experience negative treatment from both management and co-workers. The remaining 17 per cent of whistleblowers who recorded mistreatment perceived it as coming from either one or the other. The fact that the single largest group - 13 per cent of all whistleblowers - perceived the mistreatment as coming from management alone, and that the risk factors for this group were more numerous, more complex and in some instances stronger in terms of significance, confirms that this is a major area for further inquiry and investment.

\section{Against-the-odds outcomes}

Chapter 5 stressed the crucial role of managers in shaping whistleblowing outcomes through their important influences on whether or not public sector employees would ultimately view reporting in a positive or negative light. The previous section found two key risk factors associated with managerial responses that come to be perceived as mistreatment, increasing the likelihood by a magnitude of four that a whistleblower will perceive their treatment this way: first, if for whatever reason the reporting path has gone external, and second, if the event has failed to result in a positive substantive outcome. This second risk factor was also prominent among those associated with co-worker mistreatment, where its presence made the odds of poor treatment more than three times greater. 
The final analyses in this section use these high-risk indicators to identify any factors associated with employee survey cases at the extreme ends of the risk spectrum. First, an analysis can be undertaken to examine the cases of 'higher-risk' respondents for whom both these high risk factors were present, but who, against the odds, did not record mistreatment by co-workers and/or management. By comparing these 'higher-risk, good-outcome' respondents with higher-risk respondents who recorded the more predictable bad outcomes, it is possible to identify any reasons why even in difficult cases some reporters manage to emerge relatively unscathed.

Second, the reverse analysis can be undertaken to examine 'lower-risk' respondents who reported wrongdoing, for whom neither of the high risk factors were present and whose cases should therefore have been much easier for agencies to manage to a positive conclusion, yet who nevertheless still recorded mistreatment. By comparing these 'lower-risk, bad-outcome' respondents with lower-risk respondents who did not record bad outcomes, it is possible to identify some reasons why even more straightforward cases still result in problems. Both analyses provide insights into how whistleblowing cases might be better managed.

Because the groups in each case are relatively small, these analyses are not limited to public interest whistleblowers; rather, they take in all non-role reporters, including those who reported personnel and workplace grievances. The extent to which this can influence the outcome is discussed. As the statistical tests for this section could not be repeated using logistic regression, alternative significance tests were used.

\section{Positive treatment of higher-risk reporters}

When employees who report wrongdoing are at higher risk of mistreatment but, against the odds, do not record it, are there distinctive factors that explain these better-than-expected outcomes? Such cases are clearly valuable for their potential insights into how whistleblowers might be more effectively protected in a wide range of high-risk situations. In these cases, the report did not result in any substantive improvement in relation to the alleged wrongdoing, despite the reporter having pursued the matter outside the organisation, yet the reporter recorded being treated well or the same by co-workers and management as a result of the process.

Table 6.8 sets out the features of this group, comparing first those who recorded good and bad treatment by management, and secondly those who recorded good and bad treatment by co-workers. The group is small $(\mathrm{n}=105)$, making up less than 7 per cent of all reporters. Nevertheless, these respondents were spread widely across the employee survey agencies, suggesting this less common combination of outcomes could potentially arise in any agency. Despite the fact 
that the analysis now includes all reporters, including those whose reports concerned personnel or workplace grievances, all the risk factors identified in the previous section hold, but now in reverse. For those treated well, it remained the case that the wrongdoing was perceived as less serious, occurred less frequently, was less likely to have been directed at the reporter personally, was less likely to have involved multiple wrongdoers or wrongdoers more senior than the reporter and involved an immediate work unit of 20 or more people.

Only one new factor emerged as providing additional 'protection' for reporters, further reducing the likelihood of mistreatment by co-workers, notwithstanding the otherwise high risks of this occurring. This factor was the reporter's age, with reporters who escaped mistreatment by co-workers being significantly older (mean of 46 years) than those who recorded mistreatment (mean of 40 years). This result suggests that, again, power differentials are in play, with older employees better able to ride out the storm even when the risks of mistreatment are otherwise high. In all other respects, however, no magic answer emerged from this analysis. This result confirms that, if agencies are to minimise the risks of whistleblower mistreatment, this can reliably be pursued only through policies and processes that offset the many situational and outcome variables that currently contribute to poor outcomes and by actively intervening in the normal operations of the organisation, rather than letting 'natural' organisational processes take hold. 
Table 6.8 Significant factors for treatment of higher-risk reporters (mean, per cent)

\begin{tabular}{|c|c|c|c|c|}
\hline \multirow[b]{2}{*}{ Risk factor } & \multicolumn{4}{|c|}{ Means and frequencies } \\
\hline & $\begin{array}{l}\text { (1a) Treated } \\
\text { well/same by } \\
\text { management } \\
(n=33)\end{array}$ & $\begin{array}{l}\text { (1b) Treated } \\
\text { badly by } \\
\text { management } \\
(\mathrm{n}=71)\end{array}$ & $\begin{array}{c}\text { (2a) Treated } \\
\text { well/same by } \\
\text { co-workers } \\
\text { (n }=81)\end{array}$ & $\begin{array}{l}\text { (2b) Treated } \\
\text { badly by } \\
\text { co-workers } \\
(\mathrm{n}=24)\end{array}$ \\
\hline $\begin{array}{l}\text { The wrongdoing was frequent } \\
1=\text { just this once } \\
5=\text { all the time }\end{array}$ & $3.24^{* \prime}$ & $3.82^{* *}$ & $3.52^{*}$ & $4.04^{\circ}$ \\
\hline $\begin{array}{l}\text { The age of the wrongdoer (years) } \\
\text { How became aware of wrongdoing? }\end{array}$ & n.s. & n.s. & $46.21^{*}$ & $40.23^{*}$ \\
\hline $\begin{array}{l}\text { Directed at me }(n=60) \\
\text { Not directed at me }(n=44)\end{array}$ & $\begin{array}{c}15 \%(9)^{* * *} \\
55 \%(24)^{\ldots *}\end{array}$ & $\begin{array}{l}85 \%(51)^{* *} \\
45 \%(20)^{* *}\end{array}$ & $\begin{array}{l}\text { n.s. } \\
\text { n.s. }\end{array}$ & $\begin{array}{l}\text { n.s. } \\
\text { n.s. }\end{array}$ \\
\hline How many people involved? & & & & \\
\hline One $(n=19)$ & n.s. & n.s. & $95 \%(18)^{\circ}$ & $5 \%(1)^{*}$ \\
\hline $\begin{array}{l}\text { A few/large number/ widespread ( } \mathrm{n} \\
=85 \text { ) }\end{array}$ & n.s. & n.s. & $73 \%(62)^{\circ}$ & $27 \%(23)^{\circ}$ \\
\hline Position of wrongdoer & & & & \\
\hline Below or at same level $(n=23)$ & $57 \%(13)^{* *}$ & $44 \%(10)^{* *}$ & n.s. & n.s. \\
\hline Higher level $(n=81)$ & $25 \%(20)^{* *}$ & $75 \%(61)^{* *}$ & n.s. & n.s. \\
\hline Size of immediate work group & & & & \\
\hline Less than $20(n=57)$ & $21 \%(12)^{*}$ & $79 \%(45)^{*}$ & n.s. & n.s. \\
\hline 20 or more $(n=46)$ & $43 \%(20)^{\circ}$ & $57 \%(26)^{\circ}$ & n.s. & n.s. \\
\hline
\end{tabular}

n.s. $=$ not significant

* difference statistically significant at $\mathrm{p}<0.05$

" difference statistically significant at $\mathrm{p}<0.01$

difference statistically significant at $\mathrm{p}<0.0005$

Source: Employee survey: Q21, Q23, Q24, Q25, Q39, Q49.

\section{Negative treatment of low-risk reporters}

When employees who report wrongdoing are at lower risk of mistreatment but nevertheless still record it, are there distinctive factors that continue to explain these worst of all outcomes? Such cases might be considered a classic 'reprisal scenario', in which the reporter loyally kept the matter internal to the organisation and regarded their report as having been vindicated, but they were still made to suffer. In this case, the perception of mistreatment cannot be attributed simply to whistleblower dissatisfaction with the outcome, because there is less basis for conflict about the truth of the matter or frustration over inaction. What factors are associated with these outcomes?

Table 6.9 sets out the features of this group, comparing first those who recorded good and bad treatment by management and, second, those who recorded good and bad treatment by co-workers. Despite the fact that the analysis now includes all reporters, all the risk factors identified in the previous section still hold. For those treated poorly, it remained the case that the wrongdoing was perceived as more serious, occurred more frequently, was more likely to have been directed 
at the reporter personally and involved wrongdoers more senior than the reporter, with more than one wrongdoer involved.

Table 6.9 Significant factors for treatment of lower-risk reporters (mean, per cent)

\begin{tabular}{|c|c|c|c|c|}
\hline \multirow[b]{2}{*}{ Factor } & \multicolumn{4}{|c|}{ Mean and frequencies } \\
\hline & $\begin{array}{c}\text { (1a) Treated } \\
\text { well/same by } \\
\text { management } \\
(n=390)\end{array}$ & $\begin{array}{l}\text { (1b) Treated } \\
\text { badly by } \\
\text { management } \\
(n=20)\end{array}$ & $\begin{array}{l}\text { (2a) Treated } \\
\text { well/same by } \\
\text { co-workers } \\
(\mathrm{n}=390)\end{array}$ & $\begin{array}{l}\text { (2b) Treated } \\
\text { badly by } \\
\text { co-workers } \\
(\mathrm{n}=20)\end{array}$ \\
\hline $\begin{array}{l}\text { The wrongdoing was serious } \\
1=\text { not at all, } \\
5=\text { extremely }\end{array}$ & $3.89^{* *}$ & $4.45^{* \prime \prime}$ & $3.88^{* \cdots}$ & $4.63^{* * * *}$ \\
\hline $\begin{array}{l}\text { The wrongdoing was frequent } \\
1=\text { just this once, } \\
5=\text { all the time }\end{array}$ & $2.64 "$ & $3.30^{* *}$ & n.s. & n.s. \\
\hline How became aware of wrongdoing? & & & & \\
\hline Directed at me $(n=104)$ & $89 \%(92)^{* \cdots * *}$ & $12 \%(12)^{* \cdots}$ & n.s. & n.s. \\
\hline Not directed at me $(n=306)$ & $97 \%(298)^{\cdots \cdot}$ & $3 \%(8)^{\cdots \cdots}$ & n.s. & n.s. \\
\hline How many people involved? & & & & \\
\hline One $(n=215)$ & n.s. & n.s. & $98 \%(211)^{*}$ & $2 \%(4)^{* *}$ \\
\hline $\begin{array}{l}\text { A few/large number/ widespread }(n= \\
183 \text { ) }\end{array}$ & n.s. & n.s. & $92 \%(168)^{*}$ & $8 \%(15)^{*}$ \\
\hline Position of wrongdoer & & & & \\
\hline Below or at same level $(n=253)$ & $98 \%(248)^{\cdots * *}$ & $2 \%(5)^{\ldots \cdots *}$ & $98 \%(244)^{* * *}$ & $2 \%(5)^{* *}$ \\
\hline Higher level $(n=149)$ & $90 \%(134)^{\cdots \cdot}$ & $10 \%(15)^{* \cdots}$ & $90 \%(132)^{* *}$ & $10 \%(14)^{\cdots}$ \\
\hline Number of reporting stages & & & & \\
\hline Only $1(n=236)$ & $98 \%(231)^{* *}$ & $2 \%(5)^{*}$ & $97 \%(222)^{\circ}$ & $3 \%(6)^{*}$ \\
\hline More than $1(n=174)$ & $91 \%(159)^{* *}$ & $9 \%(15)^{* *}$ & $93 \%(161)^{*}$ & $8 \%(13)^{*}$ \\
\hline Investigation into report & & & & \\
\hline Yes $(n=385)$ & $96 \%(369)^{* *}$ & $4 \%(16)^{* *}$ & n.s. & n.s. \\
\hline No/don't know $(n=21)$ & $81 \%(17)^{* *}$ & $19 \%(4)^{* *}$ & n.s. & n.s. \\
\hline Employment status & & & & \\
\hline Full-time $(\mathrm{n}=358)$ & $96 \%(344)^{*}$ & $4 \%(14)^{*}$ & n.s. & n.s. \\
\hline Part-time/contractor/ casual $(n=52)$ & $89 \%(46)^{\circ}$ & $12 \%(6)^{*}$ & n.s. & n.s. \\
\hline
\end{tabular}

n.s. = not significant

* difference statistically significant at $\mathrm{p}<0.05$

** difference statistically significant at $\mathrm{p}<0.01$

*** difference statistically significant at $\mathrm{p}=0.001$

**** difference statistically significant at $\mathrm{p}<0.0005$

Source: Employee survey: Q21-5, Q28, Q33, Q46.

Three previously unidentified factors also appear to be significant in the poor outcomes of these lower-risk reporters. As none of these appears unique to personnel or workplace grievances, they can also be used to interpret the results for public interest wrongdoing.

First, even though all reporting remained internal for these groups, reporters were more likely to record mistreatment by management and co-workers if their report went through a larger number of internal stages before leading to positive action. When the number of internal reporting stages was restricted to one, reporters were much less likely to indicate poor treatment. This supports Miceli 
and Near's (1988) finding that allegations of wrongdoing that were resolved after the first report were less likely to be associated with reprisals, but that whistleblowers who were required to make their allegations in successive reports (usually to higher levels of authority) were more likely to experience retaliation. These findings further reinforce the importance of a competent initial response to a disclosure, preventing the need for a second or further report, if the chances of protecting even lower-risk whistleblowers are to be maximised. Given the evidence in Chapter 4 that most employees' first reaction is to report wrongdoing to their supervisor or another manager, irrespective of whether this is always wise, the importance of the first investigative response also reinforces the need for agencies to increase efforts for ensuring that disclosures reach the right place.

Second, the likelihood of lower-risk reporters recording management mistreatment was increased when-even though the problem was addressed - this was either without a formal investigation or without any of which the reporter was aware. When the reporter was confident that an investigation was held or, in other words, that it was their disclosure that led to the matter being addressed, close to only one in 20 from this group recorded managerial mistreatment. The mistreatment rate increased, however, to one in five of the group if the disclosure was either not investigated or the response was unknown. Given that the entire group believed that overall things became better in the organisation, it is likely that there was an investigation or other action, but clearly these reporters were not kept informed of its progress or outcome.

This result is consistent with the evidence in Chapter 5 that a failure to keep whistleblowers informed of the organisational response can contribute directly to stress and other negative outcomes. It is also likely to be an indicator of an environment conducive to direct reprisals, given that the whistleblower has not been armed with the information necessary to claim vindication and, indeed, management might have addressed the problem without any recognition or support of the whistleblower whatsoever. This result can therefore indicate a situation in which the whistleblower is correct but is either 'left in limbo' or 'hung out to dry'.

The third additional factor is the employment basis of the reporter. Lower-risk reporters who were nevertheless still treated badly by management were more than three times more likely to be employed on a part-time, casual or contract basis. Even when the level of conflict surrounding a report is otherwise low, the reporter's relative position in the organisational structure continues to be a major risk factor for reprisal. This result is consistent with other more general findings, here and elsewhere (Miceli et al. 1999), that the power of a whistleblower relative to that of wrongdoers is a direct determinant of the likelihood of negative treatment. When considering which cases deserve 
additional support and protection, it is imperative that agencies focus on low-status employees even when the risks otherwise appear low.

This section has highlighted that, for those whistleblowers with extreme levels of risk (either high or low), a number of additional risk factors come into play. If an investigation into a disclosure is kept internal to the organisation and things become better as a result, this ordinarily suggests a good outcome for the whistleblower; this group can therefore be considered 'low-risk' reporters. These analyses show, however, that, even if an investigation is conducted internally and is resolved, it is important that this occurs as early as possible (so that the whistleblower does not have to report more than once, if at all possible) and for the whistleblower's role to be recognised through advice and information. For high-risk whistleblowers (those with an unsuccessful outcome, in which the investigation was external to the organisation at some point), the results reinforce that the key to obtaining reasonable outcomes lies in assessing and compensating for the power differentials between reporters and suspected wrongdoers.

\section{Discussion and conclusions}

This chapter has emphasised that the risk of bad treatment after a report of wrongdoing does not fall evenly across all whistleblowers in all circumstances. What is it about the successful cases that makes them easier to manage? Conversely, which are the more difficult cases for whistleblowers and agencies to manage and what might be done to reduce the number of them that turn into damaging conflicts?

The first part of this chapter showed that the opportunity for effective intervention in potentially difficult cases begins with the risks inherent in the original disclosure, and in particular a more accurate understanding of the expectations held by whistleblowers at the point of disclosure. If they are to encourage internal disclosures, public sector organisations have no choice but to promise high levels of fairness, support and employee protection in response to reports of wrong doing. Given this, organisations must expect many employees to make their reports with trusting or even naive expectations and be ready to extend management protection accordingly.

Evidence from Chapter 5 and above reinforces the responsibility that lies with agencies to take an active management approach because, even when they capable of assessing the risks of reprisal from familiar sources such as co-workers, many employees are not equipped or positioned to accurately assess the factors that can cause managers to take a negative stance. The dilemma becomes how to honour the commitment to employee protection that accompanies a commitment to integrity and transparency, even in more complex cases in which management itself is implicated in wrongdoing, or is incapable of substantiating the matter. 
The second and third parts of the chapter used data from the employee survey to more closely identify the risk factors associated with the mistreatment of whistleblowers and other reporters, pointing directly to the features of these more complex cases, which demand attention. These comparisons across samples have shown that it is possible to identify a range of whistleblowing events as involving a higher risk of reported reprisals. Whistleblowers are more likely to suffer negative outcomes when the investigation of the wrongdoing is not kept internal to the organisation and does not result in an overall positive outcome. The risks of reprisal also increase if the reporter is in a vulnerable position, particularly relative to the suspected wrongdoer(s). Other basic, perhaps obvious factors, such as the seriousness and incidence of the wrongdoing, also play a role in increasing the likelihood of mistreatment.

Overall, the mistreatment reported by respondents inevitably includes many subjective elements, including a proportion of cases in which the perception of mistreatment is simply an expression of dissatisfaction with the outcome, or in which no reasonable management action could have succeeded in preventing reprisals or containing conflict. While this proportion is impossible to quantify, the results in this and the previous chapter suggest it is small. Especially when considered in light of the evidence from the case-handler and manager surveys in Chapter 5, and compared in this chapter with the different sources of perceived mistreatment, the risk factors associated with mistreatment emerge as logical products of the different situations in which almost any employee might find themselves in any organisation.

Importantly, these factors also tend to mirror many of the features present in cases in which wrongdoing is observed but not reported, identified in Chapter 3. This reinforces that when employees choose not to report because of anticipated risks of mistreatment, as discussed in Chapter 3, their assessment is probably quite reasonable. These results make it clear that if agencies are genuine about encouraging internal and regulatory reporting, they must have credible strategies for directly addressing and offsetting the risks of reprisal in these cases, and they must make these strategies readily visible and accessible to their employees.

Fortunately, the risk factors for mistreatment identified in this chapter all reflect circumstances that, while difficult to address, can indeed be targeted by special programs within agencies, by early intervention strategies and by measures to expedite external oversight of how more complex cases are being handled. The results provide insights not only into the different ways that whistleblowers themselves assess risk, but where the focus of prevention efforts can usefully lie. The analyses reinforce several needs: for whistleblowers to be actively engaged, early, in the process of assessing the risks of mistreatment or conflict surrounding their own report; for greater certainty and clarity about how the management response will unfold; for continuing communication about the 
response; and for continuing efforts to ensure that the whistleblower is receiving organisational support appropriate to the individual case. Finally, when mistreatment is not successfully prevented or contained and organisations wish their efforts to have credibility in the eyes of employees, viable mechanisms must exist for restitution or compensation.

This chapter demonstrates that, whatever the mix of strategies adopted by organisations, the process begins with an obligation to systematically 'size up' and address the risks of negative outcomes at an early stage, before stresses emerge and the trust of participants begins to unravel. With a better understanding of these risks, it is possible to identify the types of cases that should be targeted by whistleblower support programs. It is also likely that efforts to address them, through higher levels of intervention, can reduce the proportion of cases that result in reportedly bad outcomes. The types of reforms needed to realise this potential become the subject of the second part of this book. 


\section{ENDNOTES}

1 Methodology of logistic regression analysis in this chapter:

- Forward stepwise selection was performed in SPSS to identify which of the independent variables (risk factors) considered were significantly associated with the outcome variable. SPSS included the variable in the model if it was significant at the 7.5 per cent level $(p<0.075)$. (As explained below, the final model used a more stringent significance level of 5 per cent $[p<0.05]$, but a more generous criterion was used at this initial stage of model selection to avoid excluding variables of borderline significance.) The level of the exclusion criteria was 10 per cent $(\mathrm{p}>0.1)$.

- A variable was included in the final model if it was significant at the 5 per cent level $(\mathrm{p}<0.05)$. Once the likely variables to be included in the model had been determined, the final model was then rerun. Respondents who did not answer all of the questions of interest were excluded from the analysis.

- For each outcome there is an infinite number of models that could be examined and no one model should be considered as the 'correct' model. In practice, the aim is to produce a sensible, simple model. It is possible that a different selection of risk factors or an alternative method of model selection might lead to different results.

2 The risk factors initially considered in the logistic regression analysis were:

- the reporter's gender (employee survey: Q38), age (Q39), tenure with organisation (Q42), managerial status (Q44), salary (Q45), employment status (Q46)

- the type of wrongdoing $(\mathrm{Q} 20)$, its perceived seriousness $(\mathrm{Q} 22$; scale from $1=$ not at all to $5=$ extremely) and its perceived frequency (Q23; scale from $1=$ just this once to $5=$ all the time)

- whether the reporting path was internal or external $(\mathrm{Q} 28)$ and the number of stages it took (Q28)

- whether the report was kept confidential (Q29), whether the activity was investigated (Q32) and the overall outcome of reporting (Q33)

- the size of the immediate workgroup (Q49) and whether the work location was metropolitan or regional (Q50)

- whether the employee became aware of the wrongdoing because it was directed at them (Q21), whether one or more than one person was involved in the wrongdoing (Q24) and whether the position of the wrongdoer was at a higher level than the reporter (Q25).

3 Technical notes to Tables 6.6 and 6.7:

- Odds ratios indicate the strength of associations. The 'odds' of an outcome occurring is the ratio of the probability of its occurring to the probability of its not occurring. Odds ratios greater than 1 indicate that, as the predictor increases, the odds of the outcome occurring increase. Conversely, a value less than 1 indicates that, as the predictor increases, the odds of the outcome occurring decrease. The larger the size of the odds ratio, the greater is the magnitude of the association between a risk factor and an outcome.

- ' $p$ ' values indicate the statistical significance of the results by providing a measure of whether a risk factor is significantly associated with the outcome variable. A small p-value implies that it is.

- The confidence interval indicates the amount of variability and therefore the precision of the findings and the confidence that can be placed in the odds-ratio estimate. These can be interpreted as meaning that there is a 95 per cent chance that the given interval will contain the 'true' odds ratio. For example, a confidence interval of 1.3-1.8 indicates a much smaller degree of variability than one of 1.2-7.6 and is much more informative about the true magnitude of the odds ratio. 